Volume 9, No.1.4, 2020

International Journal of Advanced Trends in Computer Science and Engineering

Available Online at http://www.warse.org/IJATCSE/static/pdf/file/ijatcse0891.42020.pdf

https://doi.org/10.30534/ijatcse/2020/0891.42020

\title{
Design and implementation of an energy harvester interface circuit using ultra-low power piezo bending generator
}

\author{
Mahidur R. Sarker ${ }^{1}$, Ramizi Mohamed ${ }^{2 *}$, Sawal Hamid Md $\mathrm{Ali}^{3}$ and Masuri Othman ${ }^{4}$ \\ ${ }^{1}$ Industrial Engineering and Automotive, Nebrija University, Campus de la Dehesa de la Villa, Calle Pirineos, 55, \\ 28040 Madrid, Spain, mahidursarker@gmail.com \\ ${ }^{23}$ Department of Electrical, Electronic and Systems Engineering, Faculty of Engineering and Built Environment, \\ Universiti Kebangsaan Malaysia, 43600 Bangi, Selangor, Malaysia, *ramizi@ukm.edu.my, sawal@ukm.edu.my \\ ${ }^{4}$ Institute of Microengineering and Nanoelectronics Universiti Kebangsaan Malaysia, 43600 UKM, Bangi, \\ Malaysia,masuri@ukm.edu.my
}

\begin{abstract}
This paper presents design and implementations of energy harvesting interface circuit (EHIC) utilizing ultra-low power (ULP) piezo-bending generator PBG to run micro-devices. Conventionally, energy harvesting $(\mathrm{EH})$ devices produce low energy thus incapable to load interface with multiple applications. It is therefore support electronic drives are needed to compensate and match the load demand. In this study, an active technique electronic drives is designed and implemented for energy harvester that consists of full-wave MOSFET bridge rectifier circuit, low pass filter, step-up converter with regulator and temporary storage device. The proposed technique is simulated using PSPICE software and comparisons were made to the conventional technique on the output side. The results show that the performance of proposed technique is better than the conventional technique in terms of the output voltage. The proposed active technique generates an output up to $2.3 \mathrm{~V}$ whereas the conventional step-up converter generates an output of $0.42 \mathrm{~V}$. The proposed model EHIC simulation is run in PSPICE and implemented onto prototype board to verify the functionality. The integrated EHIC is able to generate maximum output of $1.612 \mathrm{~V}$ from an input of $0.7 \mathrm{~V}$. This corresponds to the overall efficiency of developed hardware to be greater than $74 \%$.
\end{abstract}

Key words : Energy harvester, interface circuit, low voltage, micro-devices, Piezoelectric.

\section{INTRODUCTION}

As the world energy demand is increasing, scientists are trying to explore alternatives energy to support main source of energy. The alternatives are mainly considered as renewable energy in nature like the solar, vibration, sound, wind, thermal and solid waste [1][2][3][4]. Among those, vibration based energy source has taken into considerable attention that lead ways of utilizing the technology into useful applications. Revolution in this sector has opened many streams of researchers and engineers to look for new ways to utilize piezoelectric vibration transducer for the betterment of mankind. Nowadays piezo bending generator (PBG) systems are used in almost every field of life in which the basic and important functionality is the production of power from the vibration mechanism [5][6][7]. The only limitation with vibrational mechanism is small energy level, so small up to milli or micro scale. Micro scale energy harvesting (EH) becoming equally importance of energy generations, this is due to the fact that wasted energy at micro level in nature can be harvested and utilize for another purposes. For example, heat or vibration waste energy can be harvested to supply bank of temporary energy storage [8][9].

Nowadays, vibration based piezoelectric energy harvesting technology has been evolved drastically. The evolvement through ways or techniques that the vibration is converted into some useful energy. Among those are ceramic based piezoelectric transducers, a type of semiconductive materials that can produce charge through both pressure and vibration [10][11]. The charge produced can be stored temporarily in capacitor banks and later use to supply load banks. Alternatively, it can be used to surpase the disadvantage of conventional electronic devices, in which most low power electronic devices, such as sensors and actuators rely on d.c source or battery directly. By storing the charge in super-capacitors the energy produced from PBG can be utilized later to power up the low power electronic devices.

Several modes have been identified to harvest energy based on vibration mechanism. There are three popularly known methods to harvest energy from vibration source, namely piezoelectric, electromagnetic and electrostatic [12]. Among them, energy harvesting using piezoelectric vibration transducer is well known for its long lifetime, user-friendly and simple implementation process [13][14]. The source 
mechanism by itself cannot be functioning in a standalone unit to supply for various loads, a loading effect will be the main difficulties to overcome. It is therefore, in general, to implement the vibration based piezoelectric energy harvesting system an interface circuit is required. Basically, the interface circuit is built with three core components mainly piezoelectric element (i.e. transducer), rectifier circuit and converter circuit [15].

Piezoelectricity has been identified to have capability to convert waste energy into useful electricity without 'refueling'. The only drawback to the mechanism is the low output power, however with the evolvement of power electronic drives the system mechanism can be improved significantly [16]. From another point of view, the performance of the developed system is limited by the discrepancy of the vibrator mechanism. However as new applications increase rapidly, power converter design and utilization will be common to EH system development [17]. In addition to the IoT era, the need of EH system development will be a necessity especially in the field of wireless sensor network [18]. In a place of remote area, where maintenance and battery replacement would be difficult to reach, EH system will be a better choice; in turn the implementation would only incur minor cost.

Earlier improvement of EH circuitry system focused on using passive element devices, such as low pass filter, rectifier and a boost converter. A system has been developed and implemented to improve the system efficiency using similar passive device known as synchronized switch harvesting on inductor (SSHI) and combined with piezoelectric transducer to the EH circuitry [15][19]. Yet limitation is inevitable, the system still need to have series mode connection to piezoelectric transducer for current increment and parallel mode connection for voltage increment.

This paper focuses on the development and implementation of a low power circuitry for low power micro devices. The proposed technique is simulated and analyzed using PSPICE software, later comparison is made with the conventional technique. Finally, the proposed technique is implemented in hardware and comparison is made with the results obtained from the existing methods.

\section{METHODOLOGY}

In order to develop an energy harvesting interface circuit (EHIC), the conventional drive circuitry is insufficient due to the low output level from the PBG source. The proposed modified piezoelectric EHIC components namely MOSFET, thyristor, diode, and transistors have been selected. It takes $0.7 \mathrm{~V}$ as an input from commercial PBG energy harvesting kits model EH220-A4-503YB and performed in PSPICE simulation and hardware implementation. The purpose of the proposed simulation and experiment is to uncover the advantages and efficiency. Then the simulation results and parameters obtained are transferred onto hardware implementation for verification. The flow chart of the study is shown in Figure 1.

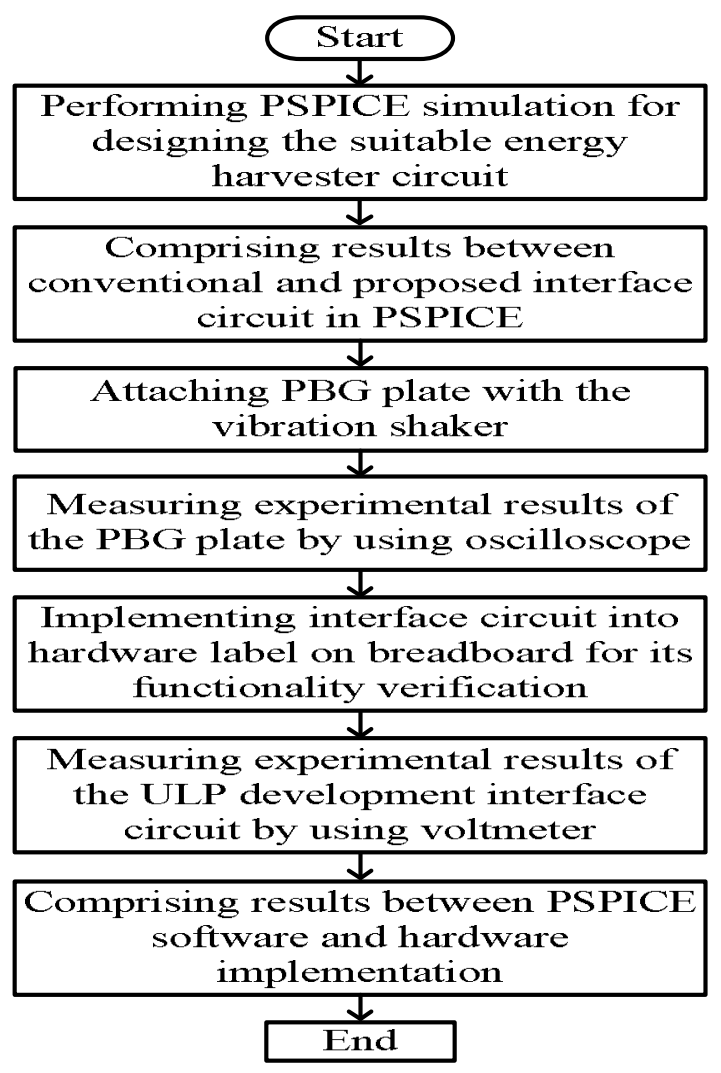

Figure 1: Flow chart of the proposed design.

\section{CONVENTIONAL ENERGY HARVESTING INTERFACE CIRCUITS}

The followings subsections outline the conventional hardware implementation for EH system implementations. In general, a conventional energy harvesting system requires three core modes; PBG, interface circuit and a storage device.

\subsection{Final Stage}

A full-wave rectifier circuit is required in order to rectify the a.c sinusoidal PBG output voltages. The rectifier is constructed using four diodes in series/parallel connection and a capacitor is connected in parallel with the output load to smooth out the d.c output ripple [20][21]. An optimum output from a full bridge rectifier can be obtained with one-half of its open circuit output voltage $V_{o c}$ as shown in Equation (1). In this case the optimum rectifier voltage $V_{\text {opt_rect }}$ will extract the maximum output charge from the PBG [20]. 


$$
V_{o p t_{-} r e c t}=\frac{V_{o c}}{2}=\frac{I_{p}}{2 \omega C_{p}}
$$

Nevertheless, a full-wave rectifier circuit consists of a temporary storage device and a resistive load, though the internal impedance of the PBG is basically capacitive. As a result the impedance matching at any point does not match. In this way the energy harvesting capability based on passive elements is considered insufficient.

Figure 2 shows the schematic circuit diagram of a conventional rectifier. A typical setup of the PBG acts as an input source to the full-wave rectifier circuits. The construction of the full-wave rectifier circuit consists of four diodes type D1N4002. The working principal of the rectifier starts by measuring the first half-cycle, when schism of the input voltage is positive and negative in polarity. At this moment only two diodes are conducting (D2) and (D4). On the other hand, first half of the sine wave is positive at top, and negative at bottom of the load. The a.c polarity is lost in the next half-cycle. At this moment, the diodes (DI) and (D3) are conducting. Besides, the segment of the circuit onwards is carrying the voltage during the last half-cycle.

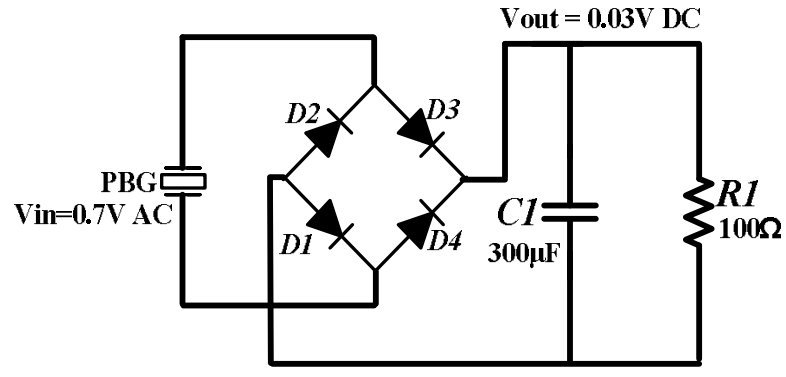

Figure 2: Conventional full-wave diode bridge rectifier.

\subsection{Conventional step-up converter}

A step up converter is also known as a boost converter. The main objective of a step-up converter is to step up the d.c output level higher than its input level [22][23]. The design of a step-up converter would normally use to meet the voltage level of a certain applications. Figure 3 shows the typical arrangement of a step-up converter that has been constructed and simulated using PSPICE software. The converter circuit contains diode, inductor and transistor with switch mode power supply. The MOSFET $M$ (IRF150) works as a switch mode power supply to the system. The inductor $(L)$ act as a temporary energy storage as a reaction to the switching operation by $M$, and the inductor current increases when the switch is closed, and the stored energy in the inductor is shifted into the load by forward conduction diode $D$ (D1N4002) when the switch $M$ is opened. At any time, whenever switch fails the effect on the inductor voltage fail to back or reverses. As a result the inductor current is not able to shift directly to the load. Under normal circumstances, the voltage across the inductor rises to a value that is higher than the combined voltage across the diode and the output capacitor. So quickly the value is extended and the diode began producing voltage at the point junction across the capacitor. As a result the output voltage increases higher than the input voltage level.

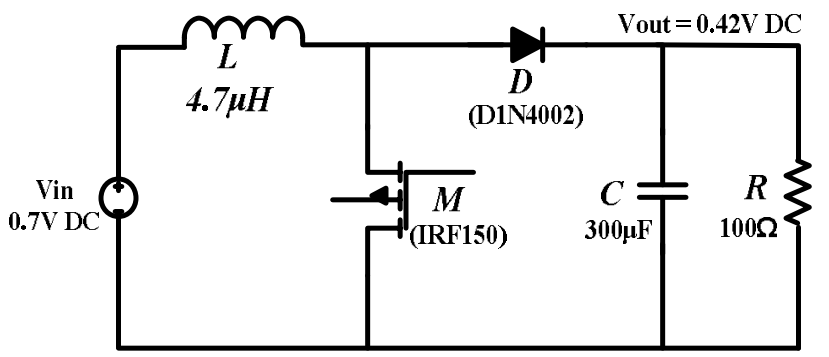

Figure 3: Conventional step-up converter

\section{PROPOSED ENERGY HARVESTING INTERFACE CIRCUITS}

This section presents the modeling of energy harvesting system using piezoelectric elements by considering the PBG, rectifier, low pass filter, boost converter and storage device. Figure 4 shows the proposed block diagram of the energy harvesting module. The active technique has been proposed to the design based on PBG, modified active switch mode power supply and temporary storage device with super capacitor.

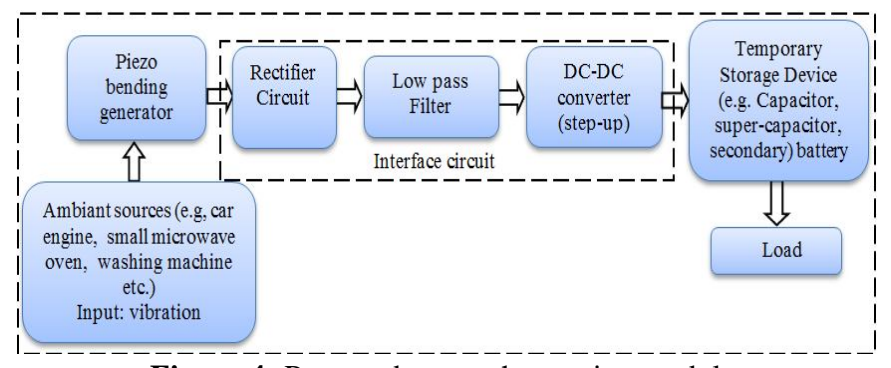

Figure 4: Proposed energy harvesting module

\subsection{Piezoelectric elements}

Piezoelectric elements are solid state materials that can generate electricity with the application of some incentive such as heat, stress, light, force and vibration. Piezoelectricity is a mutual coupling between mechanical strain or stress and electrical field and charge. This is defined through Equations from (2) and (3).

$$
\begin{aligned}
& M_{q r}=m_{q r s t}^{F} J_{q r}+b_{q r a} E_{a} \\
& G_{b}=b_{c s t} J_{q r}+\varepsilon_{a c}^{T} E_{a}
\end{aligned}
$$


Where $M_{q r}$ and $J_{q r}$ represent the mechanical strain and stress sensors, and $\mathrm{Gb}$ and Ea represent the electric displacement and field vectors. PZT is the material that generates electrical charge by pressure or vibration. PBG is one kind of energy harvesting transducer that converts the mechanical energy into useful electrical charge. The PBG is the mechanical vibration-based energy harvesting system that produces an a.c like output, whose output voltage need to be rectified before being supplied to a load. A piezoelectric device is often defined in the following Equations

$$
\begin{aligned}
& Q=C V+p F \\
& d=p V+\frac{F}{s}
\end{aligned}
$$

Where $d$ represents the deflection or displacement of the device, $Q$ represents the electrical charge, $\mathrm{F}$ represents the force applied, $V$ represents the voltage through the electrodes, $s$ represents the stiffness of the device, $p$ represents the piezoelectric coefficient, and $C$ represents the capacitance in constant force.

\subsection{Proposed rectifier circuit with filter}

This section describes the proposed design of a MOSFET based full-wave bridge rectifier circuit with an input voltage of $0.7 \mathrm{~V}$ and input frequency of $120 \mathrm{~Hz}$.

The design active technique proposed in this study is shown in Figure 5. A commercial type PBG is used as an input to the full-wave MOSFET bridge rectifier circuits that will be implemented later in the hardware section. The power MOSFET of type IRF140 has been selected to develop the MOSFET bridge rectifier in replacement to diodes. For the device to work, the entire period system is based on the pulse switching mechanisms by the MOSFETs. Five power MOSFETs has been used to develop the full-wave rectifier circuit. PBG acts as an input to the system, with positive cycle conduction drives by MOSFET $M 1$ and $M 3$ operated in forward-biased to conduct the current. The voltage is produced across resistor $R l$, which generates positive half across during the first input cycle. By this period, the other MOSFETs $M 2$ and $M 4$ are reverse-biased. On the other hand, $M 2$ and $M 4$ are forward-biased when the input cycle becomes negative. The current holds in the same direction across $R I$ during the positive half-cycle in which during the negative half-cycle, $M 1$ and $M 3$ are reverse-biased. To avoid this, MOSFET $M O$ had been used that could switch for the first half of every half cycle. The d.c output across the load $R I$ is filtered out by using capacitor $C 1(300 \mu \mathrm{F})$ which assumed to be large enough so that the output voltage is essentially constant and smooth.

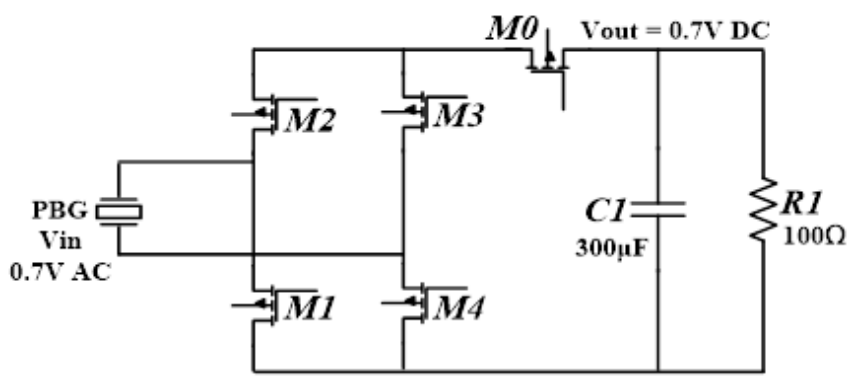

Figure 5: Proposed MOSFET based full-wave bridge rectifier.

\subsection{Proposed step-up converter}

Due to low voltage of the PBG output, a boost converter is required to complete the EH system. It is the third step of the circuit arrangement in the EH module proposed. In this study, an active technique of step-up converter has been developed as shown in Figure 6. The proposed technique has an amplification capability up to $2.3 \mathrm{~V}$ d.c output, with and input of $0.7 \mathrm{~V}$ d.c. The output voltage of the step-up converter can be calculated by using Equation 6 .

$$
V_{\text {out }}=\frac{1}{1-d} V_{\text {in }}
$$

where $V_{\text {out }}$ represents the output voltage, $d$ represents duty cycle, and $V_{\text {in }}$ represents input voltage of the PBG

The proposed simulation has an input voltage of Vin $=0.7 \mathrm{~V}$, a duty cycle $\mathrm{D}=60 \%$, load resistor $\mathrm{R}=100 \Omega$, Rise time $5 \mathrm{~ns}$, Fall time 3ns, delay time 9ms, Pulse width (PW) $0.7 \mathrm{~ms}$, and Period of 20ms. MOSFET (M5) IRF150 has been selected for power switching purposes. The device has a capability of quick switching with quick rise time and quick fall time in ns.

The current in inductor $(L)$ increases when the MOSFET control switch (M5) is at OFF state. Consequently, when the switch MOSFET is ON, the energy is transferred into the inductor. Then, the save energy is shifted to the load via the thyristor $(X)$ 2N5061 that makes the inductor current falls. In order to achieve acceptable ripple current the inductor value $4.7 \mu \mathrm{H}$ is chosen at a low duty cycle as well as at peak input voltage.

The proposed thyristor $(X)$ is used as an alternative to diode due to the fact that it has low voltage drop compared to diode and the drawback forwarding voltage of diode higher than the input voltage. The capacitor $(C)$ value of $300 \mu \mathrm{F}$ is used for charge storage and filtration. From the simulation the parameter value for resistor $\mathrm{R}=100 \mathrm{k} \Omega$ is chosen to achieved for best output, which $V_{\text {out }}=2.3 \mathrm{~V}$ was reached after utilizing the step-up converter and the simulation results are compared with hardware results as presented in later section. 


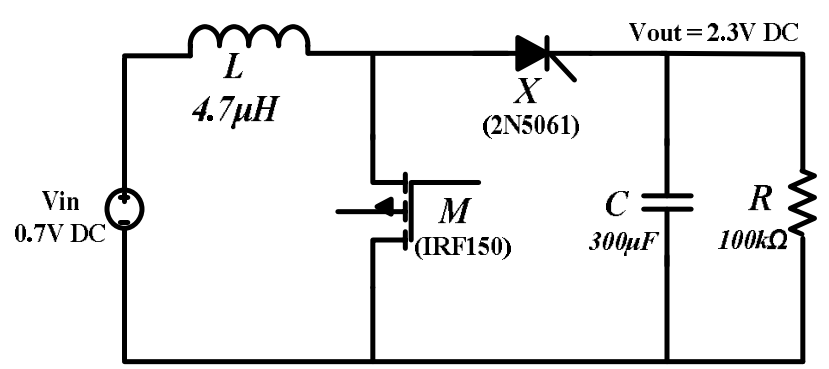

Figure 6: Development of the step-up converter

\subsection{Full proposed integrated energy harvesting system in PSPICE}

The completed EH system is designed with PBG, full-wave MOSFET bridge rectifier, low pass filter, step-up converter with voltage regulator and temporary storage devices that integrates between the rectifier and converter. The circuit diagram is presented in Figure. 7. The functions of the integrated EH system circuit is as follows: the source of input from the ambient source PBG and a rectifier circuit need to converts a.c signal into d.c. To stabilize the PBG output, a voltage regulator circuit is developed to control the rectified voltage. To perform this, the regulator is developed with an op-amp $(U)$ prior to the $L 1$ inductor to avoid unintended voltage dropped. The op-amp also becomes part of voltage compensator and buffer to the input converter in order to protect from loading effect. As previously mention, the step up converter is to convert the $0.7 \mathrm{~V}$ d.c output to its desired value right after the regulator. The component Thyristor $(X I)$ is used to replace the diode developed in the model. An inductor $(L 1)$ of $4.7 \mu \mathrm{H}$ is used to store the current prior to next cycle conduction to charge the capacitor; the $300 \mu \mathrm{F}$ capacitor becomes a temporary storage to supply the load.

\section{EXPERIMENTAL SETUP}

Figure 8 shows the device experimental setup needed to carry out the hardware implementation. The $\mathrm{EH}$ bender is a pre-mounted piezoelectric bending generator. The energy is generated with a vibration shaker to bend the cantilever structures controlled by an amplifier unit. The amplifier unit has two parameters control namely vibrational frequency and vibrational amplitude. The output waveforms can be viewed in an oscilloscope with data acquisition device and link to a computer.

\subsection{Piezoelectric cantilever beam of the PBG}

The input source of the developed integrated EHIC has a single PBG unit mounted with a piezoelectric cantilever beam. Figure 9 shows the cantilever beam applied in the system with detail parameters tabulated in Table 1. The cantilever is fixed at one end and the other is free to move. The output power is produced when the PBG is applied with bending and stress control by the amplifier unit.

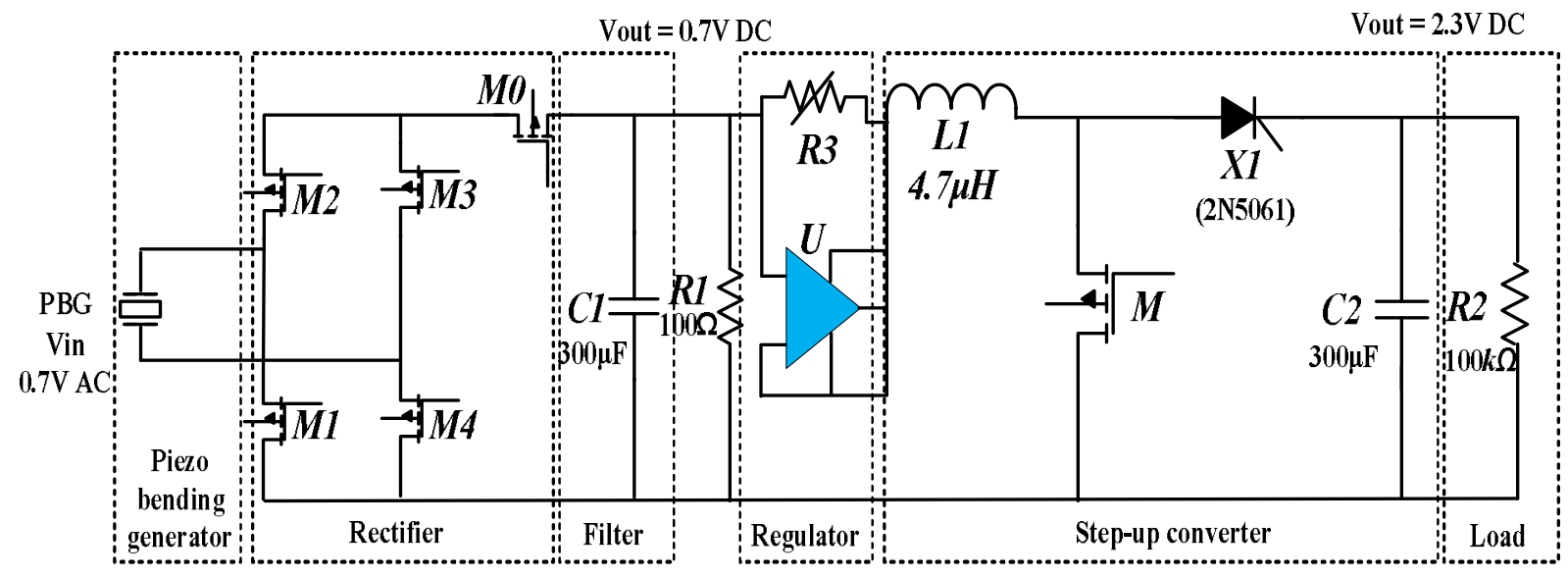

Figure 7: Simulation model of completed energy-harvesting system

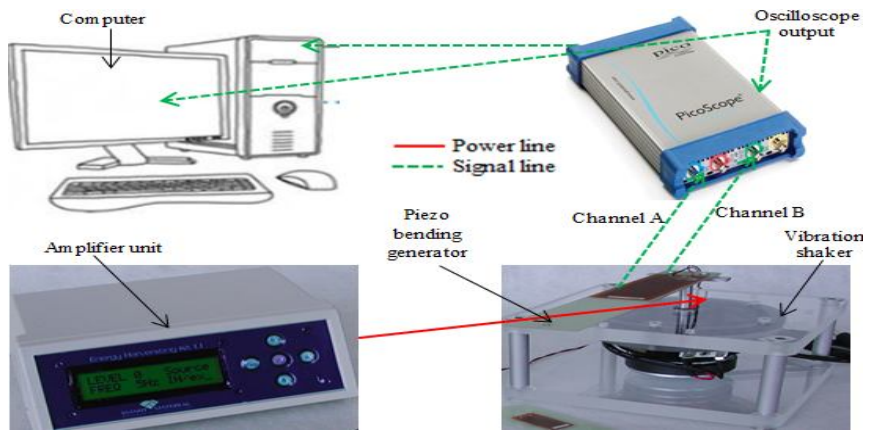

Figure 8: Experimental test bench layout

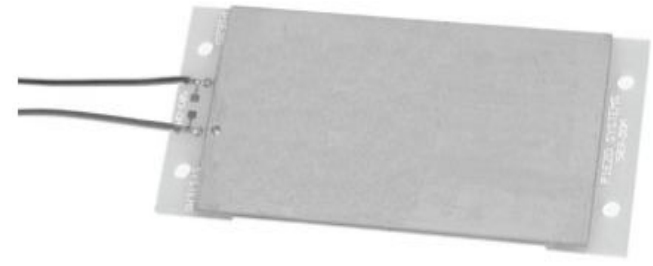

Figure 9: Piezoelectric cantilever beam of the PBG 
Mahidur R. Sarker et al., International Journal of Advanced Trends in Computer Science and Engineering, 9(1.4), 2020, 49- 58

Table 1: Piezoelectric parameters

\begin{tabular}{|l|c|c|}
\hline \multicolumn{1}{|c|}{ Parameter } & $\begin{array}{c}\text { Piezo bending } \\
\text { generator }\end{array}$ & Units \\
\hline Piezo material & $5 \mathrm{~A} 4$ & $\mathrm{E}$ \\
\hline Weight & 10.4 & $\mathrm{grams}$ \\
\hline Stiffness & $1.9 \times 102$ & $\mathrm{~N} / \mathrm{m}$ \\
\hline Capacitance & 232 & $\mathrm{nF}$ \\
\hline Rated tip deflection & \pm 2.6 & $\left(\mathrm{~mm}_{\text {peak }}\right)$ \\
\hline $\begin{array}{l}\text { Max. rated } \\
\text { frequency }\end{array}$ & 52 & $\mathrm{~Hz}$ \\
\hline $\begin{array}{l}\text { Open circuit } \\
\text { voltage }\end{array}$ & \pm 20.9 & $\mathrm{Vpeak}$ \\
\hline $\begin{array}{l}\text { Closed circuit } \\
\text { current }\end{array}$ & \pm 57 & $\mu \mathrm{Apeak} / \mathrm{Hz})$ \\
\hline Rated output power & 7.1 & $\mathrm{mWrms}$ \\
\hline
\end{tabular}

\section{RESULTS AND DISCUSSION}

This section presents the simulation and hardware implementation results of the EHIC and comparison with the proposed active system.

\subsection{Simulation results of full-wave rectifier}

Figure 10 shows the simulation results of the diode bridge rectifier in comparison with the full wave MOSFET bridge rectifier. Figure 10a) shows the simulated controlled PBG output with $0.7 \mathrm{~V}$ p-p value. The curve in Figure 10b) shows the conventional rectified output voltage with a loading effect down to $0.03 \mathrm{~V}$ with an input voltage of $0.7 \mathrm{~V}$. The curve also shows that the output voltage rises gradually after $3 \mathrm{~ms}$. The proposed rectifier circuit of Figure 10c) has significant improvement while maintaining the output to $0.7 \mathrm{~V}$ d.c. The result also shows that the output ripple has a smoothing effect as a result of filtration.

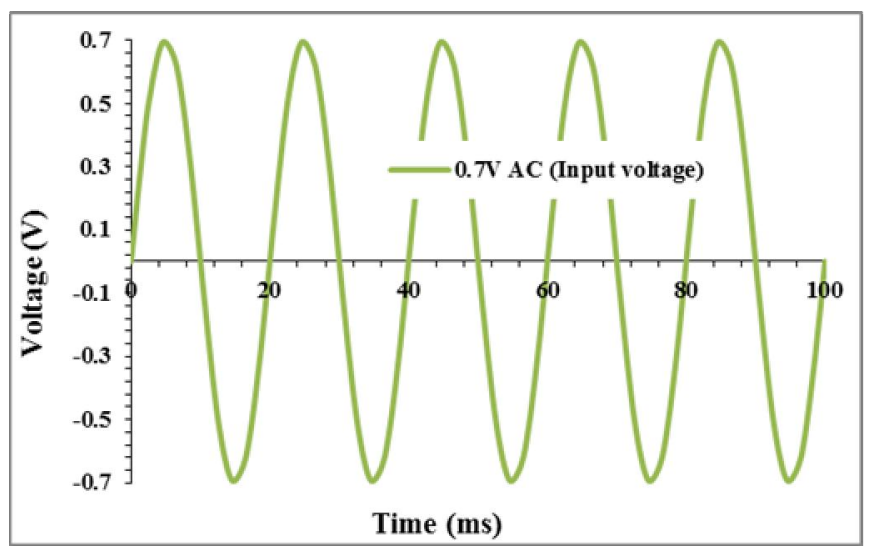

a)

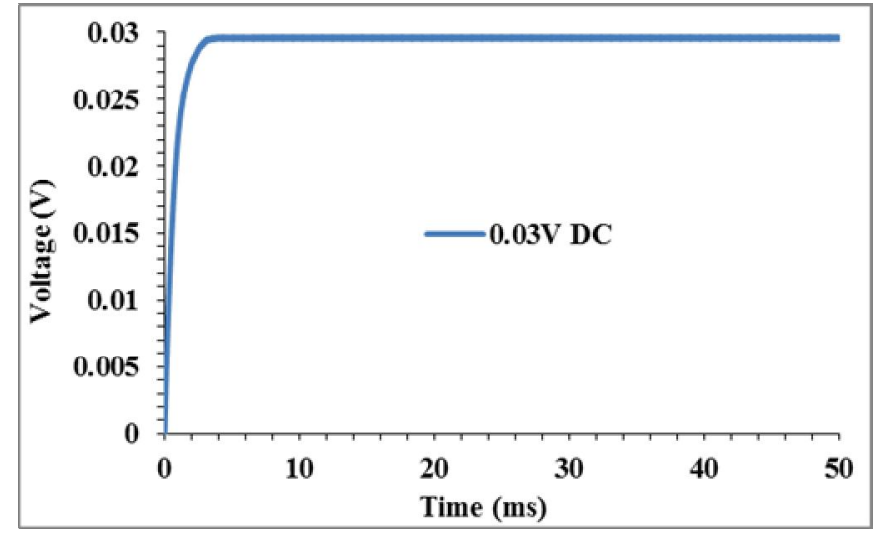

b)

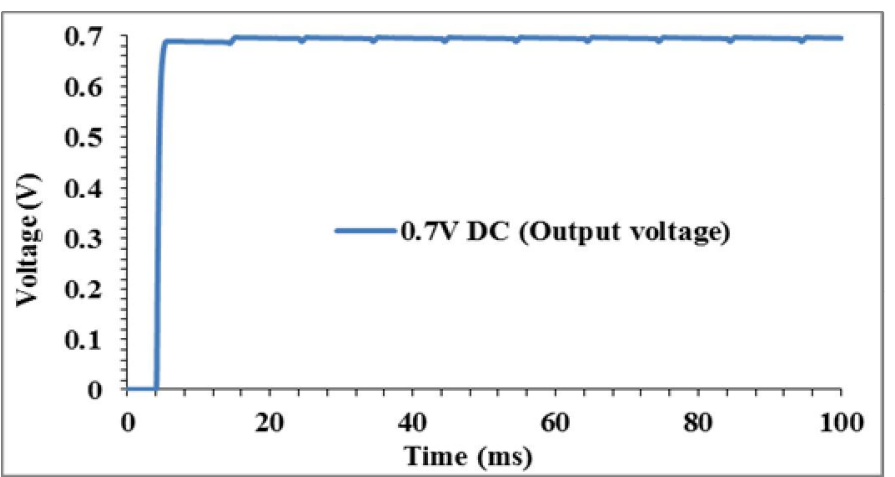

c)

Figure 10: a) Simulated output from PBG. b) Result of the conventional full-wave rectifier. c) Result of the full-wave MOSFET bridge rectifier.

\subsection{Simulation results of step-up converter.}

Figure 11 shows the simulation results of the step-up converter. Figure 11a) shows the results of an input voltage of the step-up converter of $0.7 \mathrm{~V}$ and the output response of $0.42 \mathrm{~V}$ with unstable output ripple. Whereas Figure 11b) shows the output of voltages rise and drop based on the duty cycle. Nevertheless, the performance of voltage is close to the targeted value of $2.3 \mathrm{~V}$ when duty cycle of $150 \mathrm{~ms}$ is used. With $150 \mathrm{~ms}$ duty cycle the voltage is increased gradually until it reached a saturation level of the desired value after $150 \mathrm{~ms}$ delay.

The final output response of the step-up converter is shown in Figure 11c). It can be observed that with the input voltage of $0.7 \mathrm{~V}$ d.c stability is achieved with no loading effect on the PBG side. Consequently from the output response of the proposed step-up converter, an output of $2.3 \mathrm{~V}$ is achieved after $70 \mathrm{~ms}$ step response until it stabilized. 
Mahidur R. Sarker et al., International Journal of Advanced Trends in Computer Science and Engineering, 9(1.4), 2020, 49- 58

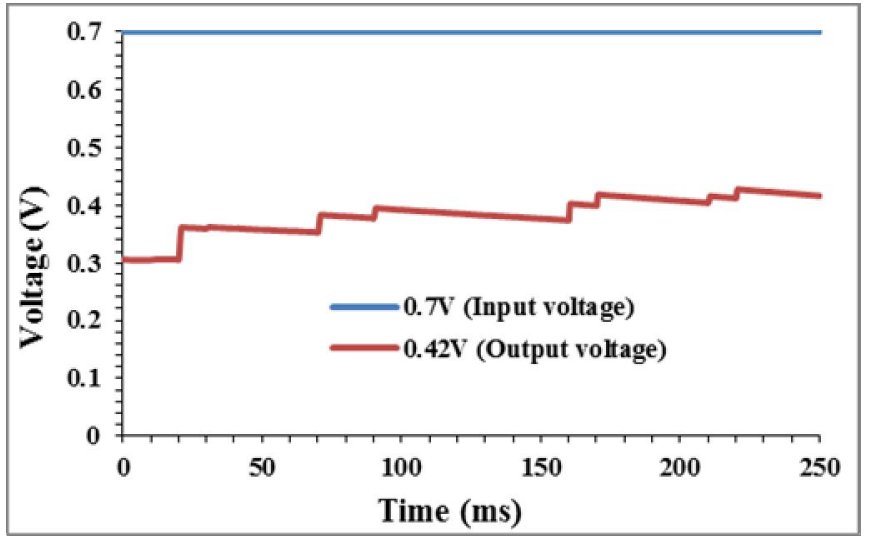

a)

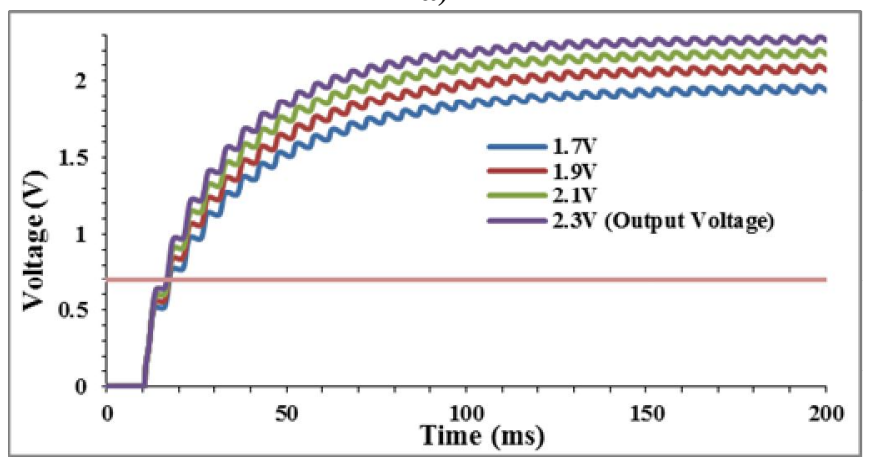

b)

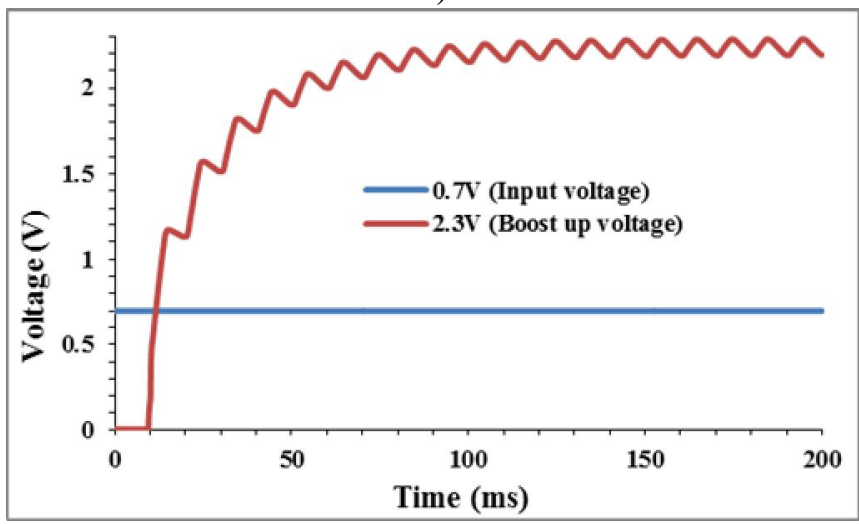

c)

Figure 11: a) Results of the conventional step-up converter. b) Result of the proposed step-up converter with different pulse width. c) Output of the proposed step-up converter.

\subsection{Simulation outcomes of the fully proposed EH system}

The final outcome of the energy harvesting system model is shown in Figure 12. The graph shows the corresponding output of the voltage and its corresponding current on the load side. The time range set for both voltage and current is between $0 \mathrm{~ms}$ to $250 \mathrm{~ms}$. As shown in Figure 12a), the input curve of $0.7 \mathrm{~V}$ d.c achieved stability in $5 \mathrm{~ms}$ and the corresponding output voltage increase gradually and achieved stability level after $60 \mathrm{~ms}$. On the other hand, Figure $12 \mathrm{~b}$ ) indicates that the current increased gradually and achieved saturation after $55 \mathrm{~ms}$ and stability is achieved. Finally, the integrated energy-harvesting circuit gain stable voltage of $2 \mathrm{~V}$ and output current of nearly $0.2 \mathrm{~mA}$.

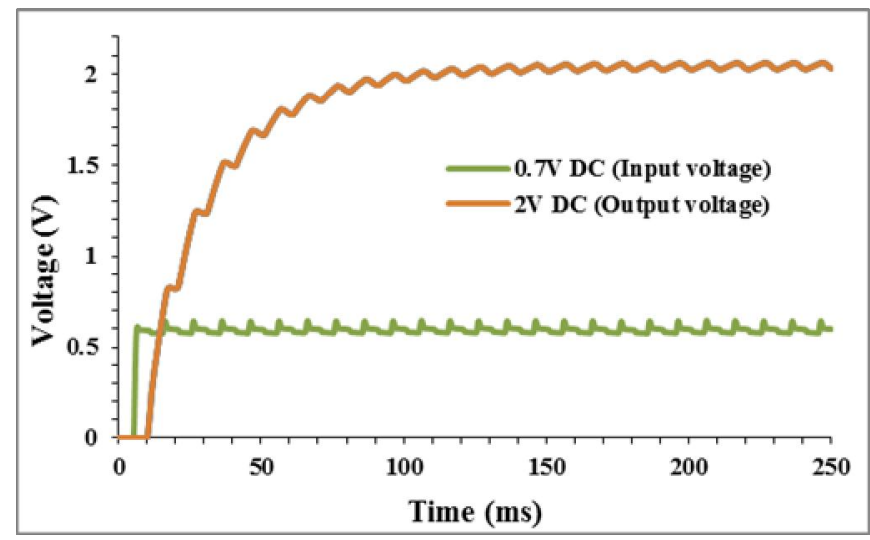

a)

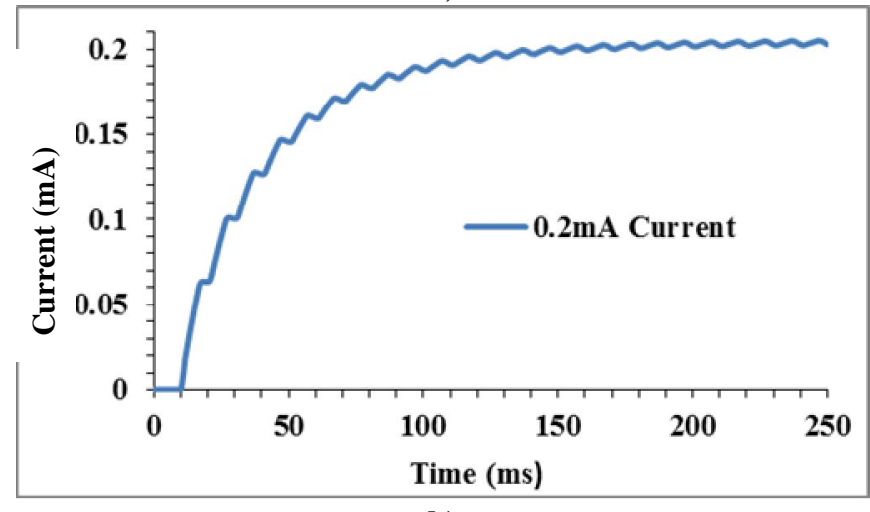

b)

Figure 12: a) Output voltage of overall EH system. b) Output current of overall EH system.

\subsection{Equipment consideration for hardware implementation}

The equipment under consideration for the hardware development implementation are tabulated in Table 2.

Table 2: Equipment list for experimental setup

\begin{tabular}{|c|c|c|}
\hline Equipment Name & Equipment Model & $\begin{array}{c}\text { Equipment } \\
\text { Quantity }\end{array}$ \\
\hline MOSFET & IRF 150 & 6 \\
\hline Thyristor & $2 \mathrm{~N} 5061$ & 1 \\
\hline $\begin{array}{c}\text { Operational } \\
\text { amplifier chip }\end{array}$ & $\mathrm{UA741}$ & 1 \\
\hline Inductor & $2.10 \mathrm{mH}$ & 1 \\
\hline Capacitor & $300 \mu \mathrm{F}$ & 1 \\
\hline Resistor & $100 \mathrm{k} \Omega$ & 1 \\
\hline $\begin{array}{c}\text { Piezo bending } \\
\text { generator }\end{array}$ & $\mathrm{EH} 220-\mathrm{A} 4-503 \mathrm{YB}$ & 1 \\
\hline Digital voltmeter & $\mathrm{CD} 800$ & 1 \\
\hline Prototype board & & 1 \\
\hline Oscilloscope & PicoScope 6000 & 1 \\
\hline
\end{tabular}




\subsection{Generated input signal from PBG}

Figure 13 shows a snapshot of hardware implementation setup of the PBG, with an output a.c voltage delivering to the next module circuitry. Figure 14 shows the experimental output results of the PBG with an input voltage with frequency of $32 \mathrm{~Hz}$, Vrms of $0.7 \mathrm{~V}$ and Vp-p of $2.67 \mathrm{~V}$..

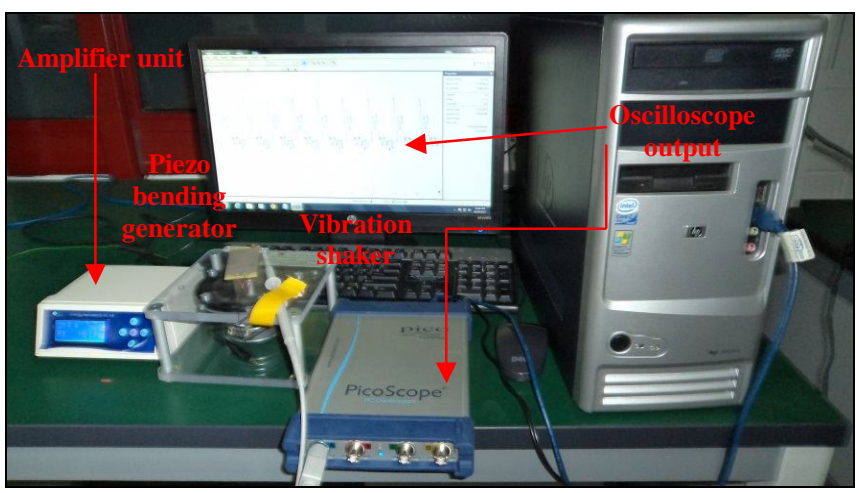

Figure 13: a) Experimental setup of the PBG energy harvester

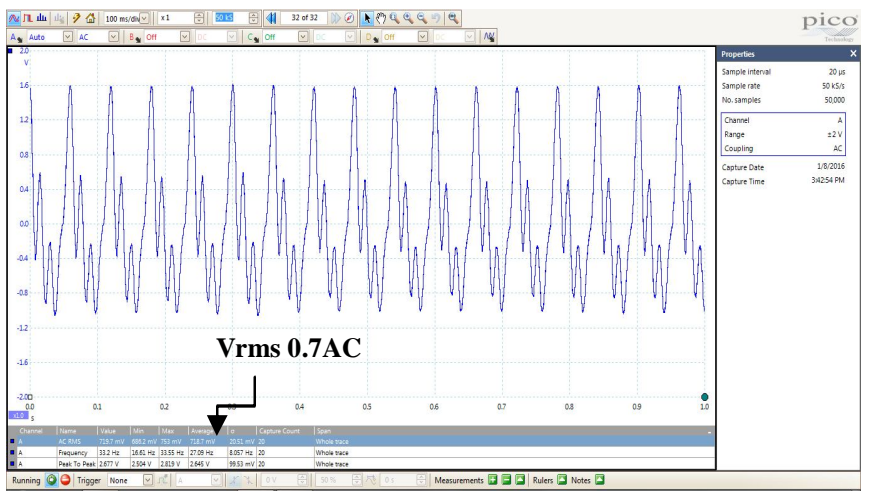

Figure 14: Experimental output voltage swing of the PBG

\subsection{Implementation of the full energy harvesting circuit}

The integration of EHIC involves numerous module segments namely rectifier, step-up converter with voltage regulator and temporary storage device. As shown earlier in Figure 7 of the circuit arrangement, Figure 15 shows the full hardware implementation of the system. The output generated from the load measurement shows a stable measured voltage of $1.612 \mathrm{~V}$ d.c. The whole schematic of EHIC is implemented on the prototype board and each result was measured with a voltmeter. Table 3 shows the comparison results between PSPICE simulation and experimental.

Table 4 shows the comparison results of existing and current work. From this table it is obvious that the proposed approach can obtain higher optimal output voltage compared to other methods. The overall efficiency of proposed circuit is shown in table 5 .

\section{CONCLUSION}

This paper presented PBG based active energy harvesting system with interface circuit to generate power for micro-devices. The proposed active energy harvester interface circuit was simulated in PSPICE software and then implemented in hardware prototype board. The simulation and hardware results of the proposed technique were compared with the conventional techniques. The results show that the output voltage obtained by the active technique has more output value than that obtained by the conventional techniques. In hardware implementation, the maximum output voltage obtained was $1.612 \mathrm{~V}$ for an input voltage of $0.7 \mathrm{~V}$. The overall efficiency of the energy harvesting circuit was found to be $74 \%$, as depicted by the hardware implementation.

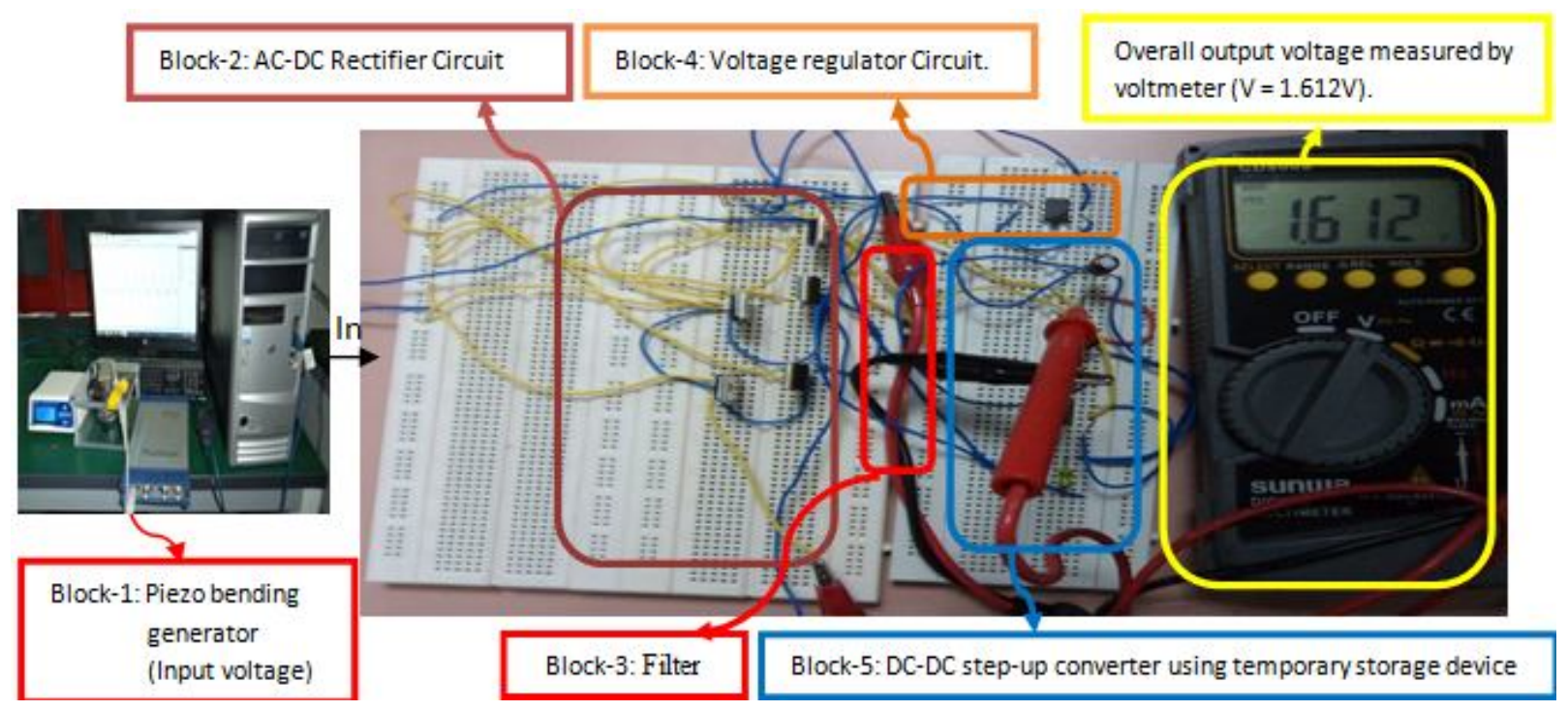

Figure 15: Implementation of completed ULP energy harvesting interface circuit with overall generated voltage of 1.612V d.c. 
Mahidur R. Sarker et al., International Journal of Advanced Trends in Computer Science and Engineering, 9(1.4), 2020, 49- 58

Table 3: Comparison results between PSPICE simulation and experiment

\begin{tabular}{|c|c|c|c|c|c|c|}
\hline $\begin{array}{l}\text { Different } \\
\text { modules } \\
\text { of energy } \\
\text { harvester }\end{array}$ & Frequency & $\begin{array}{l}\text { Vin (Input } \\
\text { voltage for } \\
\text { simulation } \\
\text { in PSPICE }\end{array}$ & $\begin{array}{l}\text { Vrms } \\
\text { (Input voltage } \\
\text { for Hardware } \\
\text { implementation }\end{array}$ & $\begin{array}{l}\text { Output } \\
\text { voltage of } \\
\text { PSPICE } \\
\text { simulation }\end{array}$ & $\begin{array}{l}\text { Output voltage } \\
\text { in Hardware } \\
\text { implementation }\end{array}$ & $\begin{array}{l}\text { Application } \\
\text { for } \\
\text { micro-device } \\
\text { s }\end{array}$ \\
\hline $\begin{array}{l}\text { a.c-d.c } \\
\text { rectifier } \\
\text { circuit }\end{array}$ & $32 \mathrm{~Hz}$ & $0.7 \mathrm{~V}$ & $0.7 \mathrm{~V}$ & $0.7 \mathrm{~V}$ & $0.520 \mathrm{~V}$ & \multirow{3}{*}{$\begin{array}{l}\text { Both voltages } \\
\text { of } 1.667 \mathrm{~V} \text { and } \\
1.612 \mathrm{~V} \text { can be } \\
\text { used for this } \\
\text { particular } \\
\text { application }\end{array}$} \\
\hline $\begin{array}{l}\text { d.c-d.c } \\
\text { step-up } \\
\text { converter } \\
\text { circuit }\end{array}$ & $32 \mathrm{~Hz}$ & $0.7 \mathrm{~V}$ & $0.512 \mathrm{~V}$ & $2.3 \mathrm{~V}$ & $1.667 \mathrm{~V}$ & \\
\hline $\begin{array}{l}\text { Fully } \\
\text { energy } \\
\text { harvesting } \\
\text { circuit }\end{array}$ & $32 \mathrm{~Hz}$ & $0.7 \mathrm{~V}$ & $0.512 \mathrm{~V}$ & $2 \mathrm{~V}$ & $1.612 \mathrm{~V}$ & \\
\hline
\end{tabular}

Table 4: Comparison results of existing and current work

\begin{tabular}{|c|c|c|c|c|c|}
\hline Parameter & {$[\mathbf{2 4}]$} & {$[\mathbf{2 5}]$} & {$[\mathbf{2 6}]$} & {$[\mathbf{2 7 ]}$} & This work \\
\hline $\begin{array}{c}\text { Input } \\
\text { voltage }\end{array}$ & $0.12 \mathrm{~V}$ & $0.25-0.4 \mathrm{~V}$ & $0.6 \mathrm{~V}$ & $0.7 \mathrm{~V}$ & $0.7 \mathrm{~V}$ \\
\hline $\begin{array}{c}\text { Output } \\
\text { voltage }\end{array}$ & $1.2 \mathrm{~V}$ & $3.3 \mathrm{~V}$ & $1.2 \mathrm{~V}$ & $1.2 \mathrm{~V}$ & $\mathbf{1 . 6 1 2 V}$ \\
\hline Frequency & $3 \mathrm{MHz}$ & $170 \mathrm{kHz}$ & $100 \mathrm{~Hz}$ & None & $32 \mathrm{~Hz}$ \\
\hline $\begin{array}{c}\text { External } \\
\text { Componen } \\
\mathrm{t}\end{array}$ & 2 inductor & $\begin{array}{c}\text { Not } \\
\text { mentioned }\end{array}$ & $\begin{array}{c}\text { Not } \\
\text { mentioned }\end{array}$ & $\begin{array}{c}2 \mathrm{~V} \text { Buffer } \\
\text { capacitor }\end{array}$ & $\begin{array}{c}1 \text { inductor } \\
2 \text { capacitor }\end{array}$ \\
\hline Efficiency & $30 \%$ & $70 \%$ & $40 \%$ & $46 \%$ & $74 \%$ \\
\hline
\end{tabular}

\section{ACKNOWLEDGEMENT}

This work was carried out with the financial support from the Ministry of Higher Education of Malaysia and Universiti Kebangsaan Malaysia under the research grant GGP-2017-011.

\section{REFERENCES}

1. B. KanagaSakthivel, D. Devaraj, R.N. Banu, and V.A.I. Selvi, A hybrid wind-solar energy system with ANFIS based MPPT controller, J. Intell. Fuzzy Syst,. Vol. 35, pp. 1579-1595, 2018.

2. M.R. Sarker, A. Mohamed, and R. Mohamed, Implementation of non-controlled rectifier circuit based on vibration utilizing piezoelectric bending generator, Int J. Appl. Electromagn. Mech. Vol. 54, 2017. https://doi.org/10.3233/JAE-160127

3. J. Choi, I. Jung, and C.-Y. Kang, A brief review of sound energy harvesting, Nano Energy. Vol. 56, pp. 169-183, 2019.

4. M. Ibáñez-Puy, J.A. Sacristán Fernández, C. Martín-Gómez, and M. Vidaurre-Arbizu, Development and construction of a thermoelectric active facade module, J. Facade Des. Eng. Vol. 3, pp. 15-25, 2015.

5. R. Mohamed, M.R. Sarker, and A. Mohamed, An optimization of rectangular shape piezoelectric energy harvesting cantilever beam for micro devices, Int. J. Appl. Electromagn. Mech. Vol. 50, pp. 537-548, 2016.

6. A. Kumar, A. Sharma, R. Kumar, R. Vaish, and V.S. Chauhan, Finite element analysis of vibration energy harvesting using lead-free piezoelectric materials: A comparative study, J. Asian Ceram. Soc. Vol. 2, pp. 138-143, 2014.

7. P. Li, S. Gao, H. Cai, and Y. Cui, Design, fabrication and performances of MEMS piezoelectric energy harvester, Int. J. Appl. Electromagn. Mech. Vol. 47, pp. 125-139, 2015.

8. X. Jiang, X. Gu, and J. Wang, Energy harvesting from large force vibrations using a piezoelectric wafer-stack harvester, Int. J. Appl. Electromagn. Mech. Vol. 46, pp. 979-990, 2014.

9. M. Jagieła, and M. Kulik, Considerations on frequency characteristics of an electromechanical vibration energy harvesting converter with nonlinear parametric resonance, Int. J. Appl. Electromagn. Mech. Vol. 53, pp. 107-120, 2017.

10. D.W. Wang, J.L. Mo, X.F. Wang, H. Ouyang, and Z.R. Zhou, Experimental and numerical investigations of the 
piezoelectric energy harvesting via friction-induced vibration, Energy Convers. Manag. Vol. 171, pp. 1134-1149, 2018.

11. K. Tao, H. Yi, L. Tang, J. Wu, P. Wang, N. Wang, L. Hu, Y. $\mathrm{Fu}$, J. Miao, and H. Chang, Piezoelectric ZnO thin films for 2DOF MEMS vibrational energy harvesting, Surf. Coatings Technol. Vol. 359, pp. 289-295, 2019.

12. B. Yan, S. Zhang, X. Zhang, K. Wang, and C. Wu, Self-powered electromagnetic energy harvesting for the low power consumption electronics: Design and experiment, Int. J. Appl. Electromagn. Mech. Vol. 54, pp. 165-175, 2017.

13. H. Liu, T. Xu, Z. Huang, and D. Chen, Parametric design for a piezoelectric cantilever carrying oscillators to harvest multi-frequency vibration energy, Int. J. Appl. Electromagn. Mech. Vol. 41, pp. 389-405, 2013.

14. S.-M. Chen, J.-J. Zhou, and J.-H. Hu, Experimental study and finite element analysis for piezoelectric impact energy harvesting using a bent metal beam, Int. J. Appl. Electromagn. Mech. Vol. 46, pp. 895-904, 2014.

15. C. Cheng, Z. Chen, Y. Xiong, H. Shi, and Y. Yang, A high-efficiency, self-powered nonlinear interface circuit for bi-stable rotating piezoelectric vibration energy harvesting with nonlinear magnetic force, Int. J. Appl. Electromagn. Mech. Vol. 51, pp. 235-248, 2016. https://doi.org/10.3233/JAE-150093

16. S. Wang, D. Liu, J. Kan, Z. Zhang, L. Yu, and H. Xu, A piezohydraulic generator for vibration energy harvesting, Int. J. Appl. Electromagn. Mech. Vol. 46, pp. 905-916, 2014.

17. Y. Li, T. Zheng, S. Yang, and Z. Ren, A methodology for topology optimization based on level set method and its application to piezoelectric energy harvester design, Int. J. Appl. Electromagn. Mech. Vol. 59, pp. 79-85, 2019.

18. H.H.R. Sherazi, L.A. Grieco, and G. Boggia, A comprehensive review on energy harvesting MAC protocols in WSNs: Challenges and tradeoffs, $\mathrm{Ad} \mathrm{Hoc}$ Networks. Vol. 71, pp. 117-134, 2018.

19. H. Shen, H. Ji, J. Qiu, and K. Zhu, A semi-passive vibration damping system powered by harvested energy, Int. J. Appl. Electromagn. Mech. Vol. 31, pp. 219-233, 2009.

20. M.R. Sarker, A. Mohamed, and R. Mohamed, Modelling and Simulation an AC-DC Rectifier Circuit Based on Piezoelectric Vibration Sensor for Energy Harvesting System, Appl. Mech. Mater. Vol. 785, pp. 131-135, 2015.

21. M.R. Sarker, S.H.M. Ali, M. Othman, and M.S. Islam, Designing a low voltage energy harvesting circuits for rectified storage voltage using vibrating piezoelectric, in: Proc. - 2011 IEEE Student Conf. Res. Dev. SCOReD 2011, 2011.

22. M.R. Sarker, S.H.M. Ali, M. Othman, and S. Islam, Designing a battery-less piezoelectric based energy harvesting interface circuit with $300 \mathrm{mV}$ startup voltage, in: J. Phys. Conf. Ser., 2013.

23. M. Sujapradeepa, A.A.C. Asis, and S. EdwardRqjan, Performance Evaluation of a Direct AC-DC Boost Converter for Piezo-Electric Energy Harvesting System, in: 2018 Int. Conf. Curr. Trends Towar. Converging Technol., IEEE, 2018: pp. 1-5.

24. A. Richelli, S. Comensoli, and Z.M. Kovacs-Vajna, A DC/DC Boosting Technique and Power Management for Ultralow-Voltage Energy Harvesting Applications, IEEE Trans. Ind. Electron. Vol. 59, pp. 2701-2708, 2012.

25. A. Bertacchini, S. Scorcioni, M. Cori, L. Larcher, and P.
Pavan, $250 \mathrm{mV}$ input boost converter for low power applications, in: 2010 IEEE Int. Symp. Ind. Electron., IEEE, 2010: pp. 533-538.

26. Yen Kheng Tan, and S.K. Panda, Optimized Wind Energy Harvesting System Using Resistance Emulator and Active Rectifier for Wireless Sensor Nodes, IEEE Trans. Power Electron. Vol. 26, pp 38-50, 2011. doi:10.1109/TPEL.2010.2056700.

27. T. Oh, S.K. Islam, G. To, and M. Mahfouz, Powering wearable sensors with a low-power CMOS piezoelectric energy harvesting circuit, in: 2017 IEEE Int. Symp. Med. Meas. Appl., 2017: pp. 308-313. 